\title{
SISTEM INFORMASI MANAJEMEN PERSEDIAAN OBAT BERBASIS WEB MENGGUNAKAN METODE PROTOTYPE PADA APOTEK
}

\author{
Krisna Ruliyanto $^{1}$, Septi Andryana ${ }^{2}$, Aris Gunaryati ${ }^{3}$ \\ Program Studi Sistem Informasi, Universitas Nasional \\ krisnaruliyanto16@gmail.com ${ }^{1}$, septi.andryana@civitas.unas.ac.id ${ }^{2}$ \\ aris.gunaryati@civitas.unas.ac.id ${ }^{3}$
}

Submitted December 2, 2020; Revised February 28, 2021; Accepted March 14, 2021

\begin{abstract}
Abstrak
Manajemen berperan sangat penting untuk menunjang jalannya persediaan aset dan pengelolaannya. Saat ini sistem manajemen aset persediaan obat pada Apotek Kaka Bekasi masih dilakukan dengan cara komputerisasi sederhana yaitu menggunakan aplikasi Microsoft Excel dan pencatatan manual, sehingga menimbulakan berbagai macam masalah. Masalah yang dihadapi apotek tersebut adalah Manajemen aset persediaan obat dalam proses pendataan pemesanan, pembelian, penjualan tidak tercatat dengan akurat dan terintegrasi dengan baik sehingga dalam proses pencarian harus mencari satu persatu data stok obat, serta lambat dalam mengetahui obat yang akan kadaluarsa. Kurangnya keamanan dalam sistem juga merupakan suatu masalah pada apotek karena dapat diakses oleh saiapapun. Maka dari itu untuk membantu para pengelola dalam manajemen aset obat dirancanglah Sistem Informasi Manajemen Aset Persediaan Obat Berbasis Web Menggunaan Metode Prototype Pada Apotek Kaka Bekasi, perancangan sistem menggunakan UML, bahasa pemrograman PHP dengan text editor sublime dan perangkat lunak manajemen database MySQL. Hasil dari penelitian ini adalah sebuah prototype yang bisa dikembangkan lebih lanjut agar dapat menghasilkan sistem informasi manajemen aset yang dapat diimplementasikan pada Apotek Kaka Bekasi.
\end{abstract}

Kata Kunci : Manajemen Aset, Prototype, Sistem Informasi, UML

\begin{abstract}
Management plays a very important role in supporting the running of the asset inventory and its management. Currently, the drug supply asset management system at the Kaka Bekasi Pharmacy is still carried out using a simple computerized method, namely using the Microsoft Excel application and manual recording, causing various kinds of problems. The problem faced by the pharmacy is that the asset management of drug supplies in the process of recording orders, purchases, sales is not recorded accurately and is well integrated so that in the search process one has to look for drug stock data, as well as being slow in knowing which drugs will expire. Lack of security in the system is also a problem with pharmacies as it can be accessed by anyone. Therefore, to assist managers in drug asset management, a Web-based Drug Inventory Asset Management Information System was designed using the Prototype Method at the Kaka Bekasi Pharmacy, system design using UML, PHP programming language with sublime text editor and MySQL database management software. The result of this research is a prototype that can be further developed in order to produce an asset management information system that can be implemented at the Kaka Bekasi Pharmacy.
\end{abstract}

Key Words : Asset Management, Prototype, Information System, UML

\section{PENDAHULUAN}

Setiap instansi perusahaan, pendidikan dan pemerintah dipastikan membutuhkan sebuah Sistem Informasi dalam menjalankan aktivitas pekerjaannya agar lebih terarah dan teratur dalam waktu yang singkat. Teknologi Sistem informasi sangat penting dan tidak bisa dipisahkan dengan suatu proses manajemen, hampir selalu keputusan manajemen membutuhkan 
dukungan teknologi informasi termasuk manajemen asset. Manajemen aset adalah sebuah kegiatan merencanakan, pengawasan dan pengorganisasian dalam menggunakan, memperbaiki, merawat dan membeli serta menghilangkan aset secara fisik guna memaksimalkan pelayanan dan mengurangi biaya serta resiko dalam mengelola aset berwujud maupun tak berwujud dengan atau tanpa teknologi dalam menjalankan kegiatan operasional [3].

Apotek Kaka Bekasi merupakan tempat dilakukannya kefarmasian penyaluran persediaan farmasi dan alat kesehatan lain. Apotek sebagai sarana pelayanan kesehatan harus mengutamakan kepentingan pelanggan masyarakat dan berfungsi menyimpan, menyediakan, menyerahkan alat kesehatan dan perbekalan farmasi yang bermutu. Apotek Kaka berada ditengah pusat keramian kota Bekasi yang sangat padat penduduk menyebabkan banyak sekali aset obat yang dimiliki apotek tersebut dan memerlukan pengelolaan terhadap aset persediaan obat tersebut.

Oleh karena itu, dirancang Sistem Informasi Manajemen Aset Persediaan Obat Berbasis Web Menggunakan Metode Prototype Pada Apotek Kaka Bekasi sehingga pengelola bisa mengelola data aset dengan baik. Sistem manajemen aset memiliki fungsi untuk pendataan aset secara terintegrasi keseluruhan pengelolaan dan pendataan barang [2] .

\section{METODE PENELITIAN}

\section{Metode Pengembangan Sistem}

Dalam penelitian ini penulis menggunakan metode Prototype. Metode ini mengharuskan interaksi pihak pengembangan dengan client, sehingga bisa mengatasi ketidakserasian antara pengembangan sistem dengan client [3]. Metode prototype ini merupakan tehnik dalam menerapkan desain sebuah sistem.
Agar penelitian berjalan dengan lancar, maka harus memiliki sebuah desain sebuah alur penelitian sebagai rencana atau rancangan bagaimana mengumpulkan dan mengolah data agar penelitian dapat tercapai sesuai yang diinginkan.

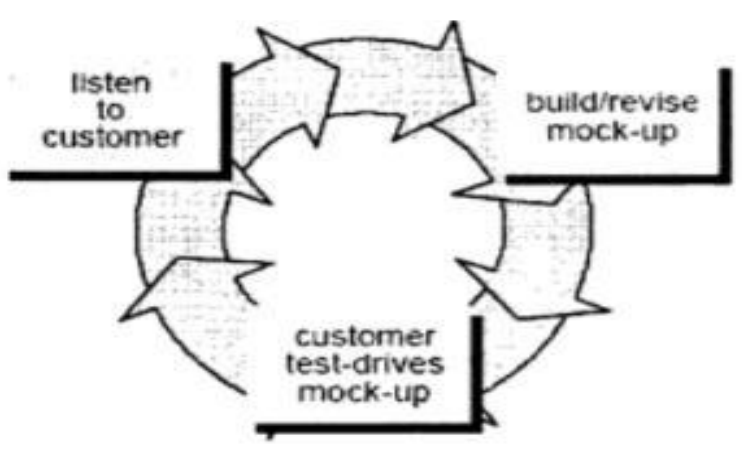

Gambar 1. Prototyping

Metode prototyping ini menampilkan visualisasi yang lengkap dari subuah sistem, model program dan kerja sistem. Pengembang mengidentifikasi kebutuhan client, menganalisa suatu sistem serta melakukan studi kelayakan meliputi tehnik procedural, user interface, dan teknologi yang akan dimanfaatkan.

\section{Metode Pengumpulan Data}

Metode pengumpulan data yang digunakan untuk mengumpulkan data sebagai kajian penulisan penelitian yang bertujuan untuk membuat rancangan sistem aplikasi adalah sebagai berikut:

1. Observasi, yaitu mengamati sekaligus pencatatan langsung pada proses bisnis di Apotek Kaka Bekasi.

2. Wawancara, yaitu melakukan tanya jawab secara langsung kepada pihak pengelola Apotek Kaka Bekasi

3. Studi Literatur, yaitu penulis mencari dan memahami teori-teori yang dapat menjadi acuan dan referensi dari internet, jurnal terdahulu dan juga buku. 
Tahap merancang sistem menggunakan metode prototype:

1. Mengidentifikasi kebutuhan client, yaitu client bersama pengembang merancang seluruh format aplikasi, mengidentifikasi kebutuhan, dan garis besar sistem

2. Merancang Prototyping, yaitu dengan melakukan perancangan yang fokus pada menu untuk client seperti membuat format input dan output.

3. Evaluasi prototyping, yaitu Tahap yang dilakukan oleh client, untuk mengetahui rancangan prototyping telah sesuai dengan yang diinginkan. Jika sesuai, tahap selanjutnya dimulai. Namun jika belum, prototyping direvisi dan mengulang tahap-tahap ke-1 dan 2

4. Mengkodekan Sistem, yaitu rancangan prototyping yang sudah disepakati diimplementasikan kedalam bahasa pemrograman

5. Menguji sistem tahap 1, yaitu setelah sistem telah menjadi aplikasi yang siap digunakan, selanjutnya dilakukan pengujian Black Box

6. Evaluasi Sistem, yaitu client mengevaluasi apakah aplikasi yang selesai dirancang sesuai denganyang diinginkan. Jika sesuai, tahap selanjutnya dimulai. Namun jika aplikasi belum sesuai dengan yang diinginkan, tahapan 4 dan 5 diulang kembali.

7. Menguji sistem tahap 2, yaitu Aplikasi yang sudah diuji dan dievaluasi client siap digunakan.

\section{Analisa Kebutuhan Sistem}

Perancangan sistem untuk membuat sistem informasi manajemen persediaan obat berbasis web ini menggunakan UML yang dibuat dengan aplikasi Star UML, bahasa pemrograman PHP dengan text editor sublime dan perangkat lunak manajemen database MySQL.

\section{HASIL DAN PEMBAHASAN}

\section{Desain aplikasi Use Case Diagram}

Dalam perancangan sistem menggunakan model berorientasi objek yaitu UML Usecase Diagram untuk mendefinisikan fungsi dari sistem.

\section{Use Case Diagram}

Use Case Diagram adalah diagram yang digunakan untuk membuat model alur proses bisnis berdasarkan pengguna sistem. Dalam diagram ini terdapat actor dan use case.

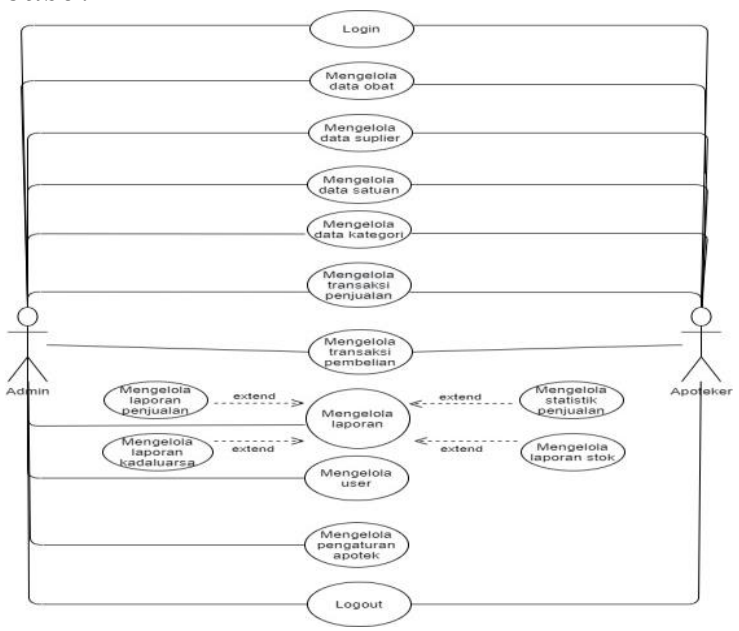

Gambar 2. Use Case Diagram

Fungsi dari actor merepresentasikan client yang ingin menjalankan sistem sebagai orang yang berinteraksi dengan sistem aplikasi, Sedangkan use case itu mempresentasikan semua operasional yang dilakukan actor.

\section{Hasil Tampilan Aplikasi}

A. Tampilan Login
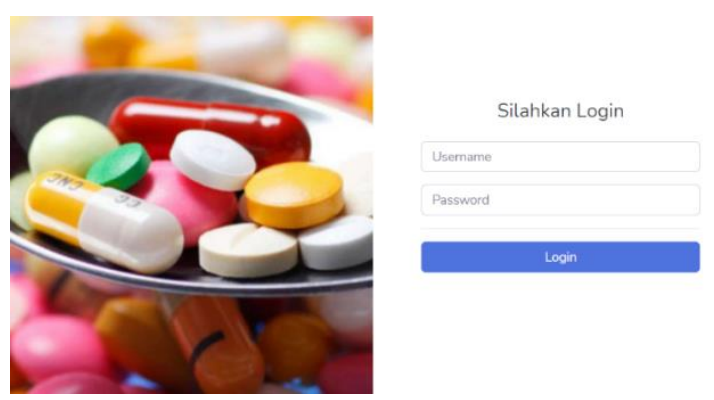

\section{Gambar 3. Tampilan Login}

Ini merupakan tampilan login untuk masuk sebagai admin atau apoteker. 
B. Tampilan Dashboard Admin

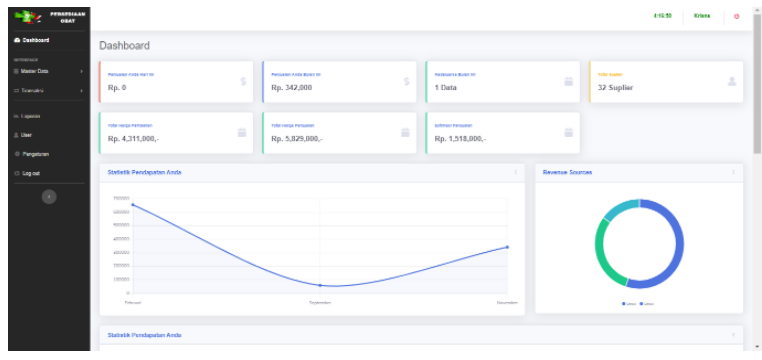

Gambar 4. Tampilan Dashboard Admin

Jika sudah login maka akan tampil menu home untuk administrator

C. Tampilan Data Obat

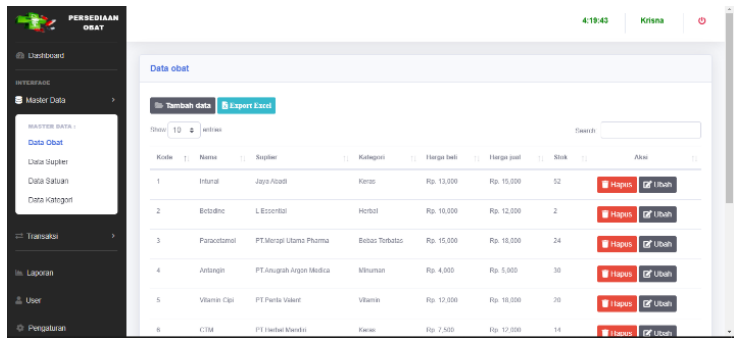

Gambar 5. Tampilan Data Obat

Pada halaman ini Admin dan Apoteker dapat menambahkan data obat yang akan disediakan di apotek

\section{Tampilan Data Suplier}
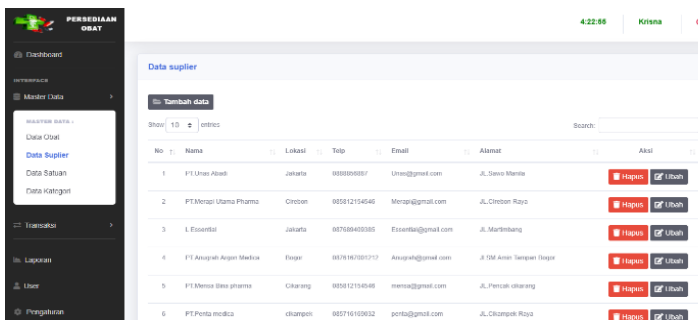

Gambar 6 Tampilan Data Suplier

Pada halaman ini Admin dan Apoteker dapat menambahkan data supplier untuk pemesanan obat
E. Tampilan Data Satuan Obat

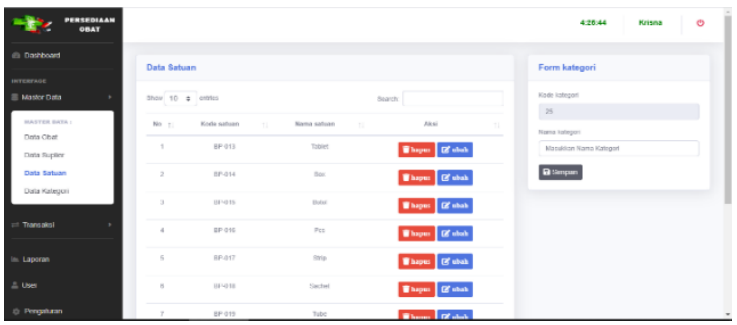

Gambar 7. Tampilan Data Satuan Obat

Pada halaman ini Admin dan Apoteker dapat menambahkan data satuan obat seperti tablet, kapsul, strip, botol dll

F. Tampilan Data Kategori

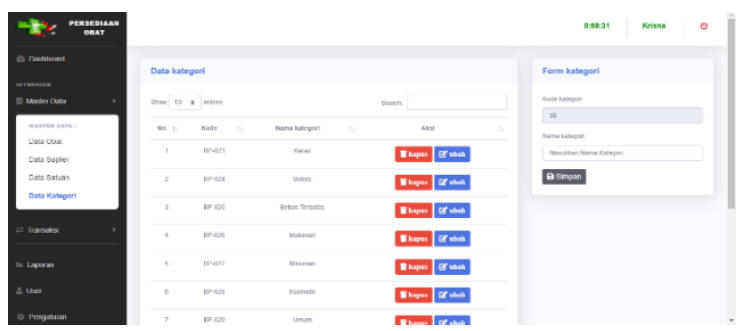

Gambar 8. Tampilan Data Kategori

Pada halaman ini Admin dan Apoteker dapat menambahkan kategori atau golongan obat seperti obat keras, narkotika, bebas terbatas, herbal dll.

G. Tampilan Transaksi Penjualan

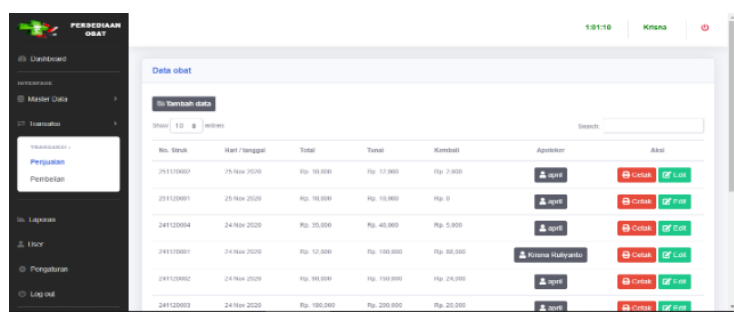

Gambar 9. Tampilan Transaksi Penjualan

Pada halaman ini Admin dan Apoteker dapat melakukan transaksi penjualan 
H. Tampilan Transaksi Pembelian

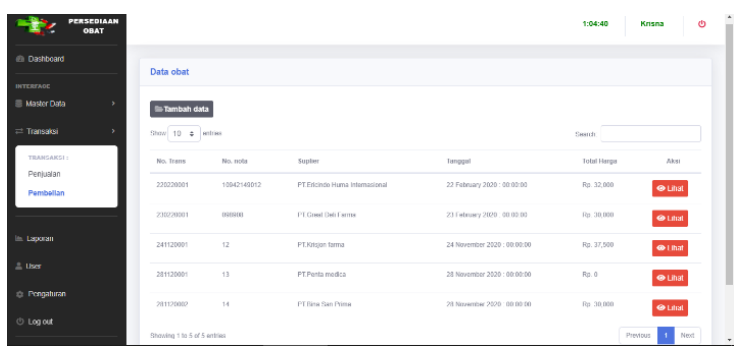

Gambar 10. Transaksi Pembelian

Pada halaman ini Admin dan Apoteker dapat melakukan transaksi pembelian obat ke supplier

\section{Tampilan Cetak Laporan}

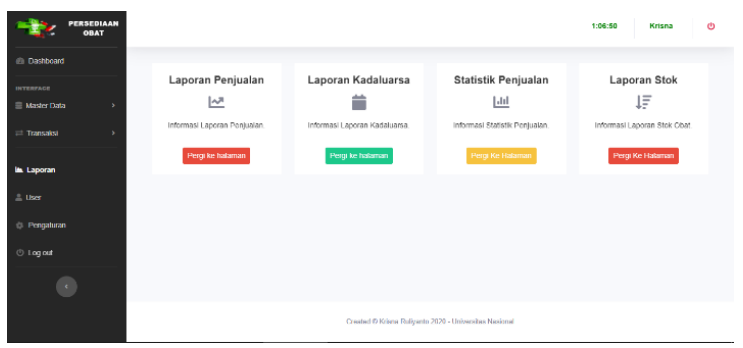

Gambar 11. Tampilan Cetak Laporan

Pada halaman ini hanya admin yang dapat mengakses dan mencetak laporan penjualan, kadaluarsa, statistik penjualan dan stok obat

\section{J. Tampilan Manajemen User}
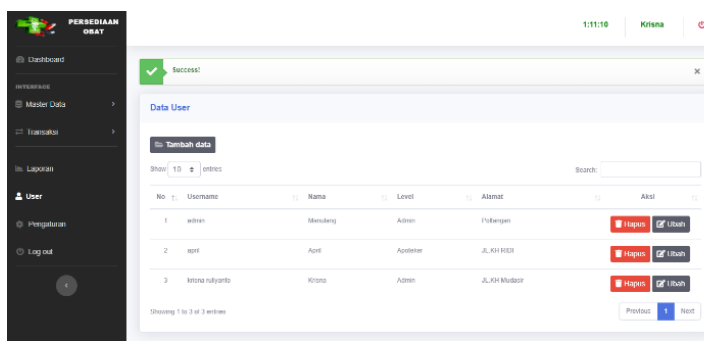

Gambar 12. Tampilan Manajemen User

Pada halamna ini hanya admin yang dapat mengakses untuk memanajemen user apoteker dan admin lainnya.
K. Tampilan Pengaturan
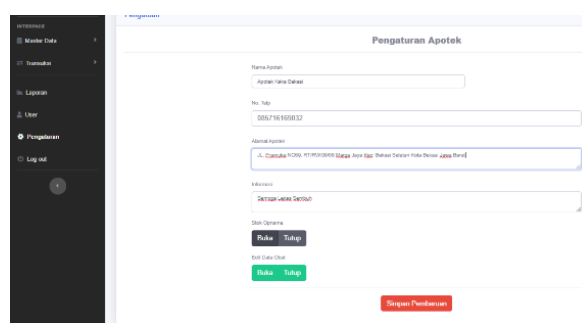

Gambar 13. Tampilan Pengaturan

Pada halaman ini hanya admin yang dapat mengakses untuk pengaturan apotek profil dan alamat apotek.

L. Tampilan Dashboard Apoteker

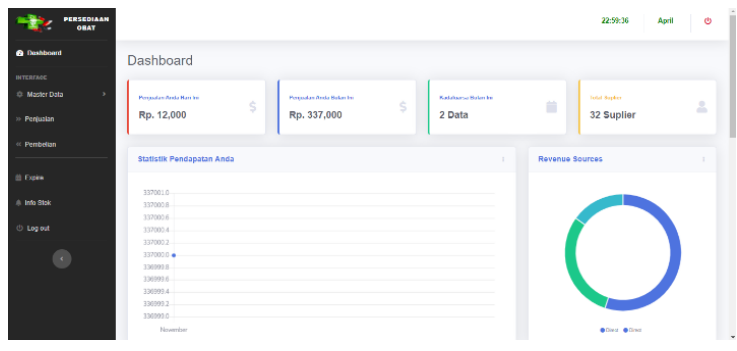

Gambar 14. Tampilan Dashboard Apoteker

Pada halaman home untuk apoteker sedikit berbeda dengan admin yaitu tidak ada kolom total harga pembelian, total harga penjualan dan estimasi penjualan

\section{M.Tampilan Data Kadaluarsa}

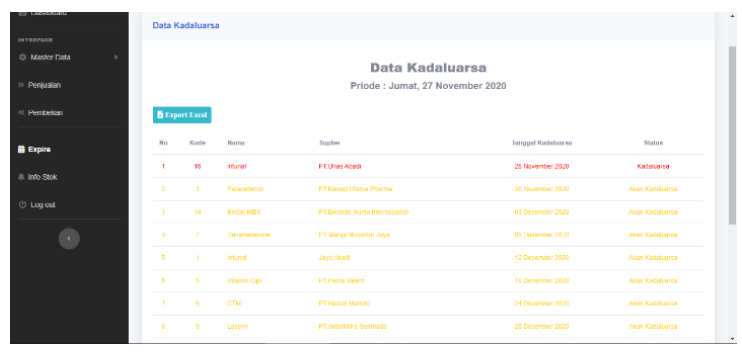

Gambar 15. Tampilan Data Kadaluarsa

Pada halaman ini admin dan apoteker dapat melihat data kapan kadaluarsa obat. 
N. Tampilan Data Stok Obat
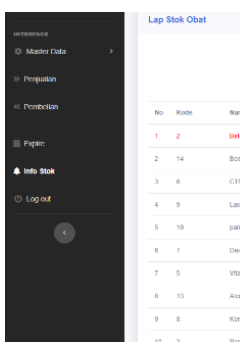

Gambar 16. Tampilan Data Stok Obat

Pada halaman ini admin dan apoteker dapat melihat persediaan obat

\section{O. Tampilan Laporan Data Obat}

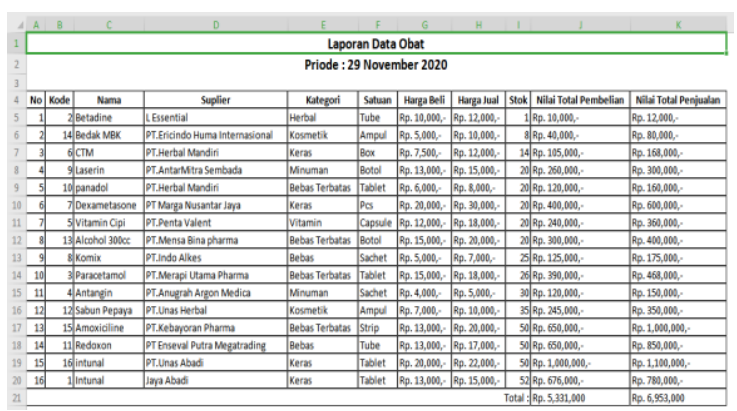

Gambar 17. Tampilan Laporan Data Obat

Ini merupakan tampilan hasil cetak laporan data obat

\section{P. Hasil Kuesioner Pengujian Tahap 2}

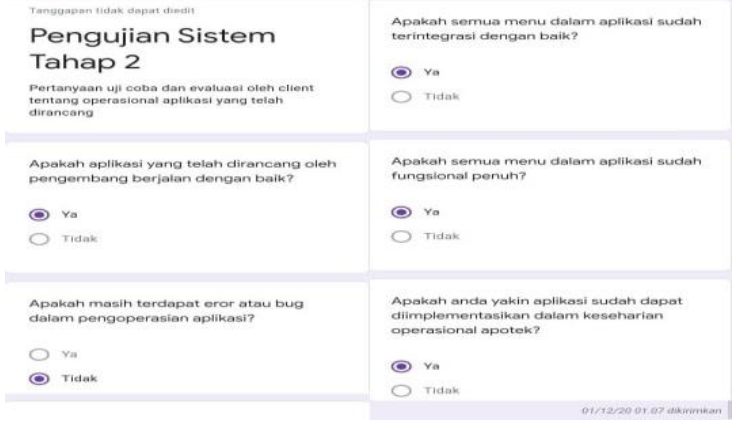

\section{Gambar 18. Hasil Kuesioner Pengujian} Tahap 2

Ini adalah hasil kuesioner pengujian dan evaluasi sistem tahap 2 oleh pengelola apotek.
Q. Pengujian Black Box

Tabel 1. Black Box

\begin{tabular}{|c|c|c|}
\hline Kasus yang diuji & Test Case & Satatus \\
\hline Halaman login & $\begin{array}{l}\text { Pengguna masuk ke } \\
\text { halaman dashboard }\end{array}$ & Berhasil \\
\hline $\begin{array}{l}\text { Menu seluruh } \\
\text { master data }\end{array}$ & $\begin{array}{c}\text { Sistem dapat } \\
\text { menampilkan dan } \\
\text { memproses semua } \\
\text { aktivitas manipulasi data }\end{array}$ & Berhasil \\
\hline Menu transaksi & $\begin{array}{c}\text { Sistem dapat } \\
\text { menampilkan dan } \\
\text { memproses semua } \\
\text { aktivitas manipulasi data }\end{array}$ & Berhasil \\
\hline Menu laporan & $\begin{array}{c}\text { Sistem dapat } \\
\text { menampilkan dan } \\
\text { mencetak laporan }\end{array}$ & Berhasil \\
\hline Menu user & $\begin{array}{c}\text { Sistem dapat } \\
\text { menampilkan dan } \\
\text { memproses semua } \\
\text { aktivitas manipulasi data }\end{array}$ & Berhasil \\
\hline Menu pengaturan & $\begin{array}{c}\text { Sistem dapat } \\
\text { menampilkan dan } \\
\text { memproses semua } \\
\text { aktivitas manipulasi data }\end{array}$ & Berhasil \\
\hline Logout & $\begin{array}{c}\text { Sistem kembali } \\
\text { menampilkan halaman } \\
\text { login }\end{array}$ & Berhasil \\
\hline
\end{tabular}

\section{SIMPULAN}

Berdasarkan hasil penelitian dalam merancang dan mengimplementasikan sistem informasi manajemen persediaan obat pada apotek Kaka Bekasi diatas dapat ditarik kesimpulan dengan adanya sistem informasi manajemen persediaan obat yang telah dirancang ini dapat membantu kesulitan yang ada pada apotek mengenai persediaan obat di apotek, memudahkan pengelolaan dalam melaporkan persediaan obat setiap bulannya, mengetahui data obat yang akan kadaluarsa dan mampu menghasilkan data yang valid yaitu data obat memiliki kesesuaian dengan kenyataan yang ada pada perssediaan di apotek. 


\section{DAFTAR PUSTAKA}

[1] J. Riyanto, "Rancang Bangun Sistem Informasi Manajemen Aset Pada Universitas Pamulang Berbasis Web," J. Inform. Univ. Pamulang, Vol. 4, No. 1, P. 9, 2019, Doi: 10.32493/Informatika.V4i1.2406.

[2] S. Dewi And L. M. Jannah, "Analisis Dan Perancangan Sistem Informasi Manajemen Aset Tetap Pada Pt . Metis Teknologi," Vol. 9, No. September, 2018.

[3] D. Purnomo, "Model Prototyping Pada Pengembangan Sistem Informasi," J I MP - J. Inform. Merdeka Pasuruan, Vol. 2, No. 2, Pp. 54-61, 2017, Doi: 10.37438/Jimp.V2i2.67.

[4] D. Gustina, S. Achmad, And A. Nuryanto, "Rancang Bangun Sistem Informasi Manajemen Persediaan Obat Pada Apotek Kimia Farma," Semin. Nas. Inov. Dan Tren, Pp. 17, 2015. 